\title{
Psycho-Pedagogical Conditions of Professional Culture Development of a University Professor
}

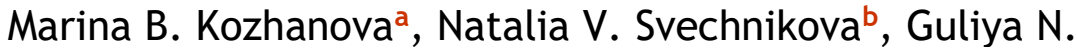 \\ Akhmetzyanovac $^{c}$ Elena N. Kondrashovad, Natalia L. Maksimova ${ }^{\mathrm{e}}$ and \\ Zhanna A. Zakharova ${ }^{f}$
}

${ }^{a}$ Chuvash State Pedagogical University named after I. Y. Yakovlev, RUSSIA; bPlekhanov Russian University of Economics, RUSSIA; 'Kazan (Volga region) Federal University, RUSSIA;

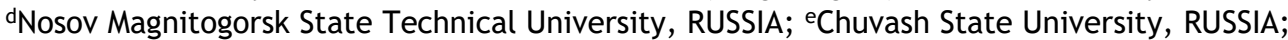

fKostroma State University, RUSSIA

ABSTRACT

The relevance of the study is conditioned by the increase of culture-forming role of university education and the increasing society demands to the professional culture of the university teacher. The purpose of the paper is to identify psychological and pedagogical conditions of development of university teacher's professional culture. The leading approach to the study is the axiological approach allowing us to consider the professional culture of the teacher as a set of scientific and pedagogical values that lead to ways of subject-subject interaction, aimed at self-improvement and increase of efficiency of scientific and pedagogical activity. The study involves 600 teachers who have identified the function of professional culture of the university teacher. The main results of the study are to identify the psychological and pedagogical conditions of development of professional culture of the university teacher (self-diagnosis and self-analysis of scientific and educational activities, the development of reflexive abilities, scientific and pedagogical cooperation with colleagues). The significance of the results obtained is that the implementation of psycho pedagogical conditions provides the development of teachers' abilities for pedagogical thinking, facilitation, reflection, generates skills of teaching improvisation, goal-setting in teaching activities.

KEYWORDS

Professional culture of the teacher, scientific and pedagogical cooperation, pedagogical thinking
ARTICLE HISTORY

Received 15 February 2016

Revised 19 November 2016 Accepted 21 November 2016

\section{Introduction}

The relevance of the study is conditioned by the increase of culture-forming role of university education and the increasing demands of society to the professional culture of the university teacher. Efficient development of university education, its training,

\section{CORRESPONDENCE M. B. Kozhanova koganova2003@mail.ru}

(C) 2017 M. B. Kozhanova et al.

Open Access terms of the Creative Commons Attribution 4.0 International License apply. The license permits unrestricted use, distribution, and reproduction in any medium, on the condition that users give exact credit to the original author(s) and the source, provide a link to the Creative Commons license, and indicate if they made any changes. (http://creativecommons.org/licenses/by/4.0/) 
developing and fostering possibility largely are reasoned by the personality of the teacher. At present, a new paradigm is approved in education - personality-oriented paradigm, which suggests that individual psychological and status characteristics of students are taken into account as much as possible in the process of teaching (Entwistle, 1981). Taking into account is carried out through educational content, the variability of educational curricula, forms and methods of teaching, the organization of the educational-spatial environment. Under these conditions, fundamentally the interaction of teachers and students is changed. Personality oriented paradigm does not tolerate the initial assignment, that puts forward new requirements for university teachers, their professional culture (Lunev \& Pugacheva, 2013). The great Russian educator of XIX century K.D. Ushinsky (1908) stresses that pedagogy by synthesizing the knowledge about the person accumulated in different sectors, should develop pedagogical theory of personality, because only a person can foster a person. It is especially important for the development of professional culture of the university lecturer, since this the process is not confined to continuous professional education system. This process is a continuous development and self-development of the teacher (Abulkhanova-Slavskaya, 1991). It is known that culture is a measure of human development, because it characterizes not only and not so much the amount of assimilated values of social life activity of people throughout their history as the way in which people is attached to these values. That is why culture embodies the way of human thinking and behavior and it covers all aspects of public life, any kind of human activity (Bibler, 1989). Culture characterizes not only education - the breadth and depth of human knowledge, but also his good manners, intelligence - the ability clearly to express their thoughts, to listen carefully, to make the right counter-movements, with dignity and in accordance with conditions to behave, etc. Culture is created by man himself, so professional culture can be presented as a special kind of culture that reflects the individual experience of the person in professional work (Iljenkov, 1991).

The professional culture of the teacher is more individual than social, as is characteristic of not only teaching state of society, but also the characteristics of the personality of a teacher. Professional culture is an important backbone factor of any specialist's professional competence, especially of a university lecturer. It becomes obvious that the success of the student's personality formation depends on the level of teacher's professional culture (Gessen, 1995). The purpose of the paper is to identify the psychological and pedagogical conditions of development of university teacher's professional culture.

\section{Research methodology}

The leading approach to the study is the axiological approach which allows us to consider the professional culture of the teacher as a set of scientific and pedagogical values that lead to ways of subject-subject interaction, aimed at self-improvement and increase of efficiency of scientific and pedagogical activity. Axiological approach allows us to allocate the subjective and objective components in the professional culture of the teacher.

The subjective component is characterized by dynamism, coupled with the improvement of teacher's personality. The objective component is characterized by mobility related to changes in the scientific and pedagogical activity of the teacher (Akhmetov et al., 2016). Based on the axiological approach, we have identified the following scientific and educational values: scientific research, innovative activity, interest in another person, respect for its originality, individuality, availability of an integrated "I - concept" sustainability, self-realization in a subject and communicative creativity, humanization of interpersonal relations, facilitation (Terentyeva, Pugacheva 
\& Lunev, 2015). Axiological approach allowed us to formulate the following conceptual idea: development of teacher's professional culture is associated with the development of reflexive processes that have an impact on a teachers' ability to integrate the scientific and pedagogical values in their scientific and professional activity.

During the research the following methods were used: theoretical (analysis, synthesis, generalization and systematization); sociological (observation, interviews and questionnaires).

\section{Results}

The main results of this study are: 1) psycho-pedagogical conditions of development of university teacher's professional culture (self-diagnosis and selfanalysis of scientific and educational activities' achievements, the development of reflexive abilities, scientific and pedagogical cooperation with colleagues); 2) experimental verification of their effectiveness.

\section{Psycho-pedagogical conditions of development of university teacher's professional culture}

The first condition is a self-diagnosis and self-analysis of scientific-pedagogical activities' achievements. The study of their own abilities, creative potential is particularly relevant for teachers (Friedman \& Kulagina, 1991). Implementation of this condition in practice, provides for the organization of special training with the use of test methods in order to develop teachers' skills to pedagogical thinking and measuring of direction (an interest in the students and the overall results of the work, responsibility), need-motivational sphere of the teacher's personality (optimism, commitment to self-improvement) the level of professional success (activity, initiative, enthusiasm, ability to self-government). It is found that the pedagogical thinking includes case studies with theoretical knowledge and acceptance on this basis of an adequate solution that provides a self-test and self-analysis of scientific and pedagogical activities' achievements. Value of pedagogical thinking is that it requires a transition from standard-descriptive type to creative type of problem solving in dynamic, unexpected, ambiguous and multifunctional situations (Kashapov, 2000). This includes identification by the teacher of properties of scientific and pedagogical activity which are not apparently set or hidden in the course of comparison and classification of different situations, identification in them of cause-and-effect relationships. The "teacher's certification"- business game was held during the training. Participants were divided into three groups: teachers who wished to be certified; members of the evaluation commission; Experts observers. During the game, members of the evaluation commission visited the "open classes" of teachers, were present at the resolution of the situations and assessed the professional culture of the teachers with the help of the proposed diagnostic features. Teachers who wished to be certified evaluated themselves. Observers-experts watched the work of the evaluation commission, discussed the validity of its decisions. It is found that during the implementation of the first condition it is necessary to consider professional culture as an integral personal formation, rather than its individual characteristics. In this case, the development of professional culture of the teacher will be successful. Professional culture will contribute to the effective students' socialization, in its turn (Petrova et al., 2016).

The second condition is the development of reflexive abilities. Reflection is the process of thinking of the individual about what is happening in his own consciousness, self-knowledge. Reflective ability is assumed to be the knowledge of the man of himself in a certain situation or a certain period, the clarification of the attitudes of the others, 
the formation of ideas about the changes that may occur (Davydov, Neverkovich \& Samoukina, 1999). To know himself as individuality, as a unique unity and uniqueness of the aggregate of individual qualities, a person may, referring to other people, separate social groups and humanity as a whole. To evaluate himself person can in the mirror of social norms and values within a certain social culture (Zavyazkin, 1998). Self-cognition is not possible without the knowledge of the culture and its interiorization. But it would be a mistake to dwell on this or assume that one first need to know the culture, and then yourself. These processes have to go at the same time, comparing of cultural values and their reflection in other people and himself. Teacher's reflective abilities ensure the development of subject-subject interaction in the process of scientific and pedagogical activity. Implementation of this condition in practice provided special training, during which the teachers proposed to rank the pedagogical and reflective characteristics of their activities on the four components of selfawareness: ideal "I", the real "I" reflexive "I" and a retrospective "I" (Berne, 1986). Pedagogical features included the ability to work with the content of educational material; to study the state of kinds of students' activity to determine the real possibilities; to select and apply a combination of forms of training and education; to focus on a learner as on actively developing subject of the pedagogical process in setting educational objectives; to foresee the consequences of pedagogical decisions; promptly to make pedagogical decisions, followed by a conscious analysis; to "set distance" (Rubtsov, 1998). Reflective characteristics combined abilities to listen and purposefully manage the process of communication with students; increase the "sensitivity of perception of himself and of other students"; use the method of selfhypnosis and self-protection in crisis periods of their professional activities; persuade and inspire; relate the difficulties of students with omissions in pedagogical work; active empathy hearing; adequate expression in communication; take responsibility (Fetiskin, Kozlov \& Manuilov, 2002). Properties' selection subjected to rankings was carried out in order to identify attitudes to different styles of scientific and pedagogical activity (authoritarian, facilitative, permissive).

The third psychological and pedagogical condition is scientific and pedagogical cooperation with colleagues. Cooperation - is one of the species of interactions, the participants of which contribute to the mutual fulfillment of a target which has become a common goal and solution of common problems. Scientific and pedagogical cooperation can be classified for various reasons: the number of participants; subject criteria; time (episodic, short-term, intermittent, continuous); the criterion of organization (systematic, chaotic); degrees of freedom (voluntary and involuntary); functions (role-playing, total); criterion of subordination (horizontal, vertical); subjective factor (active and passive). Psychological barriers are elucidated which affect the process of cooperation: 1) revaluation of details and their values, which often take precedence over the fundamental points. In these cases, in Russia they say that "to make an elephant of a fly "; 2) syndrome of someone else's fault, which is manifested in the indictment: "It's all because of you!"; 3) violation of the psychological distance; 4) the effect of contrasting concepts, that is human tendency to notice only negative things in one partner, resulting in pre-formed negative attitude, regardless of the behavior of the partner, in fact; 5) complex of differences, i.e. sustainable human non-acceptance of all that disagrees with his ideas, tastes, beliefs; 6) attempt to take out - the human tendency to direct negative emotions to an available object.

It is found that the efficiency of research and teaching cooperation is increased in terms of compatibility of group participants and interpersonal attraction. The group compatibility is characterized by: 1) psychological compatibility (similar temperaments of participants, consistency when performing certain types of work, joint activities); 2) 
emotional compatibility (mutual sympathy of participants to each other, the high level of informal affection, well-functioning communication link); 3) role-compatibility (consistency of functional-role expectations of participants); 4) the value-orientation or reference compatibility (common in the value orientations of participants. Most vivid expression of this phenomenon: "We").

The recommendations on optimization of interpersonal attraction are developed: 1) let the people feel they are unique, irreplaceable. Of course, one cannot "overdo" in all cases. If your partner will understand the lies, hardly after that relationship will be better. With the positive development of the relationship partner will to think that the formula "no one is irreplaceable," cannot be treated to him. 2) allow people to feel "native" man. Partners pretty quickly understand who in this system of relations is "native". It is important to feel corporate solidarity because it causes the alien person to become someone who is "native". 3) let people feel their significance. It is known that it is possible to instill a sense of pride in their profession, even, for example, such a minor as a janitor. 4) it is necessary to be patient listeners, since for each person his problems, mental anguish or joy mean much more than anything else . 5) remember that the sweetest and most important sound in the human voice is the sound of a person's name. Everything else is "spinning" around us, we are the center of everything. It is better therefore to pronounce the name of the partner in dialogue with him. 6) smile. The whole world has long known that the partner with an angry expression on his face did not contribute to success in business. And yet we persistently frown, thinking that stern expression is indicative of our determination, efficiency, although it is not so. But even the negative decision must be drawn by a smile so that the partner would not suspect of ill will, and realized that there was simply no other way; 7) do not skimp on compliments. As in all other cases, it is impossible to do it without knowing the partner, his features, never resort to insults, screaming and stuff, but excessive praise and a blatant lie can seriously damage business relationships with a partner.

Implementation of this condition in practice provides for the organization of special training with the aim to master the scientific and pedagogical methods of cooperation: an appeal to the interests of the parties and important for partner values; recognition of merits and social and psychological support of the partner; variant and objective offers for partner; an appeal to competent, authoritative intermediary; empathy; mutual complementarity of participants of cooperation, etc. (Carnegie, 2008). It is found that the development of scientific and educational cooperation is one of the features of university management (Kamasheva et al., 2016), as well as a means of anticorruption policies (Zamaletdinov et al., 2016).

\section{Experimental verification of the effectiveness of psycho-pedagogical conditions of development of university teacher's professional culture}

Experimental verification was carried out from 2014 to 2016. The experimental test was attended by 600 university professors of Kazan. Experimental verification took place in three stages: the ascertaining, forming and controlling.

On ascertaining stage through the survey the opinions of teachers about the content of their professional culture was determined. The overwhelming majority of teachers believe that professional culture is part of general culture (93.0\%). However, the question of what is the professional culture of the teacher was not answered by most of the respondents $(78.0 \%)$ Those who answered to this question $(22.0 \%)$ in the definition of the professional culture of the teacher included the following skills: of pedagogical knowledge applied in practice $(27.0 \%)$, to communicate with students $(9.0 \%)$, self-control (8\%), pedagogically expediently to behave $(4.0 \%)$. 
In the formative stage, taking into account the results of the survey, a special program on the organization of psycho-pedagogical conditions was developed and implemented for development of university teachers' professional culture. According to the first condition (self-diagnosis and self-analysis of scientific and pedagogical activity) were organized: 1) a special training; 2) business games; 3) group and individual counseling. According to the second condition (the development of reflexive abilities) pedagogical lecture "University teacher's culture" and special training sessions were organized. The theme of one of the trainings is "Professionalization of the individual of the teacher. The training space was limited by parameters such as: "the subject of scientific and pedagogical activity", "object of scientific and pedagogical activity", "structure of scientific and educational activities." During the training, professional and significant qualities of the teacher were identified (observation, types of memory, creative thinking, spatial imagination, attentiveness, emotional stability, determination, endurance, flexibility, perseverance, dedication, discipline, self-control, and others). These qualities were divided into four groups, which were the evidence of the existence of four main professional types of teachers, "good-natured", "intellectual", "organizer" and "homeroom." According to the third condition (scientific and pedagogical cooperation with colleagues) were organized: 1) round tables "The methods of personal and business conversations", "Group decision of logic tasks"; 2) scientific-methodical seminar "Technology of establishing contact and acquaintance", "Organization of group discussion", "Evaluation of a number of personality traits and analysis of the behavior of the interlocutor."

In the control phase during the roundtables the functions of university teachers' professional culture were identified: 1) gnostic, consisting in adequate understanding of scientific and educational activities; 2) integrative, providing integration of scientific and pedagogical knowledge, abilities and skills of research and teaching activities; 3 ) organization, providing teacher's effective planning of activities and forecasting their results; 4) communicative, which is manifested in the ability to build collaborative relationships with students and colleagues; 5) orienting, which is manifested in the formation of philosophical principles.

\section{Discussions}

In modern science, there is a certain system of knowledge, necessary and sufficient for the formulation and solution of the studied problem. Several areas of research are revealed concerning the development of professional culture of the university teacher. The first area is characterized by the development of professiogram of the teacher, which is determined by the content of theoretical knowledge of the teacher, the list of pedagogical abilities and skills, the role of professional culture (Blaga \& Shabek, 1991; Gromkova, 1993 Zeer 2003; Lunev et al., 2016). In the works of the representatives of this direction the teacher's professional culture is reduced to creative and professional activity, formation and improvement of personal qualities, personality traits, as thinking, memory, speech, etc

The second line of research, describing the structure of scientific and pedagogical activity, reveals the pedagogical aspect of the development of university teacher's professional culture (Bondarevskaya, 1995; Fontana, 1986). Under the direction of this direction the teacher's professional culture is seen as the possession by mankind of accumulated information about pedagogy, psychological processes that affect in the whole on all human life activity, including professional.

The third area of research is devoted to the organization of training of teachers to improve pedagogical skills on the basis of raising the level of professional culture (Babarshev, 1999; Noss, 2003; Sergeeva, 2002). 
The fourth line of research examines the teacher's professional culture as a component to provide the quality of educational services (Terentyeva et al., 2016; Pugacheva et al., 2016).

Despite the multifaceted nature and extensiveness of works on the issue of the development of professional culture of the university teacher, it is not considered as an integral personal formation. We believe that the teacher's professional culture is the pivotal factor in his research and teaching activities, determining its own position in science and pedagogical communication.

\section{Conclusion and recommendations}

At the present stage of development of university education the role of the teacher's professional culture is immeasurably increased. Professional culture acts as the basis of research and teaching activity of the teacher, helping not only to explain and justify theoretically pedagogical facts and processes, but also to determine scientifically justified methods of teaching, fostering and development of students. Development of professional culture of the university teacher is conditioned by the external (social and professional requirements for teacher's personality) and internal (personal characteristics and qualities that determine teacher's readiness to scientific and pedagogical activity) factors. It is found that the efficiency of development of university teacher's professional culture is increased, in case of organization of such psychological and pedagogical conditions, as a self-diagnosis and self-analysis of scientific and educational activities' achievements, the development of reflexive abilities, scientific and pedagogical cooperation with colleagues. Self-diagnosis and selfanalysis of research and teaching activities' achievements provide skills' development: consistently comprehend the situation; take into account the factors influencing the result; respond to the changes of environmental situation; to distinguish knowledge from facts. Development of reflective abilities is associated with the inherent characteristic of the scientific and pedagogical activity. Development of reflective abilities provides orientation to the realization of a given structure of scientific and educational activities; development of abilities and skills to understand the inner world of man, to think from the perspective of the learner; formation of readiness to identify and analyze experienced professional difficulties and updating their personal meaning. Scientific and pedagogical cooperation with colleagues creates skills of teaching improvisation (the ability quickly to find educational solutions and implement them; the ability to combine impromptu and planned; the ability to make the best pedagogical decisions under time pressure, the ability flexibly to restructure educational goals and objectives as changing educational situation) goal-setting research and teaching activity (ability to specify objectives, formulate action plans)

The study results allow outlining prospects for further research of the problems that are associated with the development of methods of professional culture of the university teacher.

Paper submissions may be useful for managers and university professors; staff of continuous professional training and retraining centers for the selection and structuring of the content for continuous professional development of the teaching staff in universities.

\section{Disclosure statement}

No potential conflict of interest was reported by the authors.

\section{Notes on contributors}


Marina B. Kozhanova - Doctor of Education, Professor, Vice-Rector on Educational Work and Social Issues, Chuvash State Pedagogical University named after I. Y. Yakovlev, Cheboksary, Russia.

Natalia V. Svechnikova - PhD, Associate Professor of the Department of Civil Legal Disciplines, Plekhanov Russian University of Economics, Moscow, Russia.

Guliya N. Akhmetzyanova - Doctor of Education, Professor of the Department of Service of Transport Systems, Kazan (Volga region) Federal University, Kazan, Russia.

Elena N. Kondrashova - PhD, Associate Professor of the Department of Pedagogy, Nosov Magnitogorsk State Technical University, Magnitogorsk, Russia.

Natalia L. Maksimova - PhD, Associate Professor of the Department of Social and Clinical Psychology, Chuvash State University, Cheboksary, Russia.

Zhanna A. Zakharova - Doctor of Education, Professor, Head of the Department of Psychological and Pedagogical Education, Kostroma State University, Kostroma, Russia.

\section{References}

Abulkhanova-Slavskaya, K.A. (1991). The strategy of life. Moscow: Mysl.

Akhmetov, L.G., Khramova, N.A., Sychenkova, A.V., Chudnovskiy, A.D., Pugacheva, N.B., Pavlushin, A.A., Varlamova, M.V. \& Khilsher, V.A. (2016). Selective Support for the Development of Regional Vocational Education Services: the Russian Experience. International Review of Management and Marketing, 6(2), 127-134.

Babarshev, A.V. (1999). Psychological Diagnostics of ability to communicate or how to determine organizational and communicative qualities. Moscow: Humanitarian Publishing Center VLADOS.

Berne, R. (1986). The development of self-concept and education. Moscow: Progress.

Bibler, V.S. (1989). Culture. Dialogue of cultures: experience of definition. Questions of philosophy, 6, 31-42.

Blaga, K. \& Sebek, M. (1991). I'm your pupil you're my teacher. Moscow: Prosveshchenie.

Bondarevskaya, E.V. (1995). Introduction to teaching culture. Rostov-on-don: Publishing house of Rostov state pedagogical University.

Carnegie, D. (2008). How to win friends and influence people. Moscow: AST.

Davydov, V.V., Neverkovich, S.D. \& Samoukina, N.E. (1999). On the Functions of reflection in game education of managers. Questions of psychology, 3, 76-84.

Entwistle, N.J. (1981). Styles of learning and teaching. New York: Wiley.

Fetiskin, N.P., Kozlov, V.V. \& Manuilov G.M. (2002). Socio-psychological diagnostics of development of personality and small groups. Moscow: Publishing house of Institute of Psychotherapy.

Fontana, D. (1986). Teaching and Personality. Oxford: Basil Blackwell Ltd.

Friedman, L.M. \& Kulagina I.Y. (1991). Psychological Handbook of a teacher. Moscow: Education.

Gessen, S.I. (1995). Basics of pedagogy. Introduction in applied philosophy. Moscow: "Shcola-Press".

Gromkova M.T.(1993). Pedagogical bases of education of adults. Moscow: Publishing house of Moscow agricultural Academy.

Iljenkov, E.V. (1991). Philosophy and culture. Moscow: Publishing house of political literature.

Kamasheva, Y.L., Goloshumova, G.S., Goloshumov, A.Y., Kashina, S.G., Pugacheva, N.B., Bolshakova, Z.M., Tulkibaeva, N.N. \& Timirov, F.F. (2016). Features of vocational education management in the region. International Review of Management and Marketing, 6, 155-159.

Kashapov, M.M. (2000). Psychology of pedagogical thinking. Saint Petersburg: Aleteya.

Lunev, A.N., Pugacheva, N.B. \& Stukolova, L.Z. (2014). Development strategies for professional educational services under the increasing autonomy of territories within the federal state. Actual Problems of Economics, 160(1), 215-220.

Lunev, A.N., Safin, R.S., Korchagin, E.A., Sharafutdinov, D.K., Suchkova, T.V., Kurzaeva, L.V., Nikishina, S.R. \& Kuznetsova, N.A. (2016). The Mechanism of Industrial Educational Clusters Creation as Managerial Entities of Vocational Education. International Review of Management and Marketing, 6, 166-171.

Lunev, A.N. \& Pugacheva, N.B. (2013), Social practice as the philosophical basis of pedagogical strategizing in a technical College. Society: Philosophy, History, Culture, 4, 11-16.

Noss, I.N. (2003). Introduction to the technology of psycho-diagnostics. Moscow: Publishing house of Institute of Psychotherapy. 
Petrova, T.N., Kirillova, O.V., Sokolova, S.G., Pugacheva, N.B., Galimullina, A.F., Maksimova, O.G., Antonova, T.V. \& Kozhanov, V.V. (2016). Education as the Management of Research Universities Students' Socialization. International Review of Management and Marketing, 6(2), 28-33.

Pugacheva, A.S., Filippova, V.P., Kon, A.Y., Dorzhieva, L.B., Silchenok, I.S., Pugacheva, N.B., Lunev, A.N. \& Mustafina, A.A. (2016). Market Regulators of Service Spheres Innovative Development as a Tool of Regional Socio-Economic Policy. International Review of Management and Marketing, 6(2), 294-300.

Rubtsov, V.V. (1998). Joint training activities: social interaction and learning, Questions of psychology, 5, 49-59.

Sergeeva, V.P. (2002). Theoretical pedagogy in the tests and training missions. Moscow: Center for humanitarian literature "RON".

Terentyeva, I.V., Starodubtsev, M.P., Timonin, A.I., Pugacheva, N.B., Zykova, N.N., Lunev, A.N., Ezhov, S.G. \& Starikova, L.D. (2016). Assessment of state services quality and availability in the socio-cultural sphere. International Review of Management and Marketing, 6, 122-127.

Terentyeva, I.V., Pugacheva, N.B. \& Lunev, A.N. (2015), Theoretical methods the experimental work in vocational education pedagogy. Modern Problems of Science and Education, 2, 133-138.

Ushinsky, K.D. (1908) Materials for the third volume of "educational anthropology" Direct access: http://dugward.ru/library/pedagog/ushinskiy_chelovek3.html.

Zamaletdinov, R.R., Yudina, N.P., Lavrentyeva, E.I., Savva, L.I. \& Pugacheva, N.B. (2016). Practical Recommendations on the Improvement of the Effectiveness of Anti-Corruption Policy in Universities. International Review of Management and Marketing, 6, 390-396.

Zavyazkin, O.V. (1998). Self-control and self-regulation. Donetsk: Stalker.

Zeer, E.F. (2003). Psychology of professional education. Moscow: Publishing house NPO "MODEK". 